\title{
Ultrasonic motor performance influenced by lubricant properties
}

\author{
Qiu, Wei; Mizuno, Yosuke; Adachi, Koshi; Nakamura, Kentaro
}

Published in:

Sensors and Actuators A: Physical

Link to article, DOI:

10.1016/j.sna.2018.09.022

Publication date:

2018

Document Version

Peer reviewed version

Link back to DTU Orbit

Citation (APA):

Qiu, W., Mizuno, Y., Adachi, K., \& Nakamura, K. (2018). Ultrasonic motor performance influenced by lubricant properties. Sensors and Actuators A: Physical, 282, 183-191. https://doi.org/10.1016/j.sna.2018.09.022

\section{General rights}

Copyright and moral rights for the publications made accessible in the public portal are retained by the authors and/or other copyright owners and it is a condition of accessing publications that users recognise and abide by the legal requirements associated with these rights.

- Users may download and print one copy of any publication from the public portal for the purpose of private study or research.

- You may not further distribute the material or use it for any profit-making activity or commercial gain

- You may freely distribute the URL identifying the publication in the public portal

If you believe that this document breaches copyright please contact us providing details, and we will remove access to the work immediately and investigate your claim. 


\section{Accepted Manuscript}

Title: Ultrasonic motor performance influenced by lubricant properties

Author: Wei Qiu Yosuke Mizuno Koshi Adachi Kentaro Nakamura

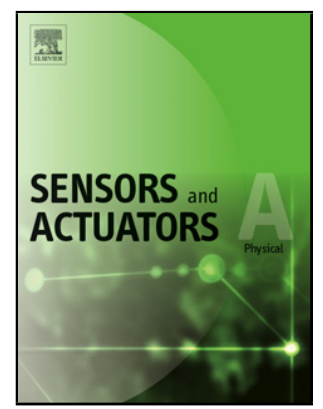

PII: S0924-4247(18)31181-6

DOI: https://doi.org/doi:10.1016/j.sna.2018.09.022

Reference: SNA 10997

To appear in:

Sensors and Actuators A

Received date: $\quad$ 16-7-2018

Revised date: $\quad 16-8-2018$

Accepted date: $\quad$ 8-9-2018

Please cite this article as: Wei Qiu, Yosuke Mizuno, Koshi Adachi, Kentaro Nakamura, Ultrasonic motor performance influenced by lubricant properties, <![CDATA[Sensors \& Actuators: A. Physical]]> (2018), https://doi.org/10.1016/j.sna.2018.09.022

This is a PDF file of an unedited manuscript that has been accepted for publication. As a service to our customers we are providing this early version of the manuscript. The manuscript will undergo copyediting, typesetting, and review of the resulting proof before it is published in its final form. Please note that during the production process errors may be discovered which could affect the content, and all legal disclaimers that apply to the journal pertain. 


\title{
Ultrasonic Motor Performance Influenced by Lubricant Properties
}

\author{
Wei Qiu ${ }^{\mathrm{a}, *}$, Yosuke Mizuno ${ }^{\mathrm{b}}$, Koshi Adachic ${ }^{\mathrm{c}}$, Kentaro Nakamura ${ }^{\mathrm{b}, *}$ \\ ${ }^{a}$ Department of Physics, Technical University of Denmark, DTU Physics Building 309, DK-2800 \\ Kongens Lyngby, Denmark \\ ${ }^{b}$ Institute of Innovative Research, Tokyo Institute of Technology, 4259 Nagatsuta-cho, Midori-ku, \\ Yokohama 226-8503, Japan \\ ${ }^{c}$ Department of Mechanical Systems Engineering, Graduate School of Engineering, Tohoku \\ University, Aoba 6-6-01, Aramaki, Aoba-ku, Sendai 980-8579, Japan
}

\begin{abstract}
Functional lubrication has been shown to be a promising method for improving the performance of ultrasonic motors (USMs). However, the complex lubrication mechanisms have not been studied and the effect of the lubricant properties on motor performance remains unknown. In this paper, both low-traction fluids and hightraction fluids with a wide viscosity range are applied, and the lubricating effects are investigated in hybrid transducer-type ultrasonic motors. The results clearly show that high-traction fluids have significant superiority to low-traction fluids in terms of motor efficiency and reduction of friction loss at the entire range of the applied preload. A high friction coefficient in boundary lubrication regime and efficient modulation in friction are confirmed to be essential for achieving high-performance lubricated USMs. It is also found that the motor performance is independent of lubricant viscosities in the tested range, irrespective of lubricant types. The reasons for the distinct lubricating effects with the two types of lubricants are analyzed in
\end{abstract}

\footnotetext{
${ }^{*}$ Corresponding authors

Email addresses: weiqiu@fysik.dtu.dk (Wei Qiu), knakamur@sonic.pi.titech.ac.jp (Kentaro Nakamura)
}

Preprint submitted to Sensors and Actuators A: Physical

August 16, 2018 
detail, which leads to the criteria of selecting lubricants and more understanding in the lubrication mechanisms in USMs.

Keywords:

Ultrasonic motors, efficiency, torque, lubricant, viscosity, lubrication mechanisms

\section{Introduction}

Ultrasonic motors (USMs) possess several unique features, e.g. high torque at low speed, high power density, precise positioning capability without using gear systems, etc., that electromagnetic motors generally do not have [1, 2]. Owing to these attractive features, USMs have been expected to have wide markets since their infancy. However, in spite of the successful application in cameras, USMs have not been considerably utilized as the actuators in other mechanical systems. Their inherently low efficiency and short lifetime are always the major obstacles, and contemporary commercial USMs are solely used for the actuation tasks where neither high-efficiency nor long-time operation is required.

The inherent problems of USMs are mainly caused by their friction drive mechanism. In most of the USMs, the alternating vibrations in both tangential (driving) and vertical (loading) directions exist. The vertical vibration varies the loading force and hence the friction force between the rotor and the stator is instantaneously changed, corresponding to the sinusoidal tangential force. Consequently, both positive (same direction as the rotational direction of rotor) and negative friction forces exist during the motor operation, and the positive friction force in one period of vibration should always be larger than the negative friction force. Friction loss is generated by the slip between the rotor and the stator, and large slip appears when negative friction force is present, which should ideally be minimized in order to achieve high motor efficiency. Though numerous attempts have been made to enhance the motor 
efficiency by designing ideal contact and vibration conditions [3, 4, ㅍ, 6, 6, 1, 8, 9, 10], by applying the friction materials with desirable tribological performance [11, 12], or by optimizing drive and control schemes [13, 14, 15], these methods are still based on friction drive mechanism and cannot effectively reduce the friction loss without sacrificing output torque. Several types of non-contact USMs, of which the rotor does not contact with the stator, have been developed to eliminate the friction loss [16, 17, 18, 19, 20]. However, the output torque of non-contact USMs is greatly lower than that of contact-type USMs, significantly limiting their applications.

In order to tackle the inherent problems in USMs, the authors proposed a novel driving mechanism, i.e. using lubrication at the contact interface, which had not been considered to be applicable to friction drive USMs. Lubricants can work in different lubrication regimes according to the contact conditions, which was described by the well-known Stribeck curve [21]. The presence of low lubricant viscosity, low relative velocity between the two contact surfaces, or high load leads to boundary lubrication regime, which usually provides a high friction coefficient. In contrast, the friction coefficient can be significantly reduced in hydrodynamic lubrication regime, which is achieved by high lubricant viscosity, high relative velocity, or low load. Mixed lubrication regime falls in between boundary and hydrodynamic lubrication regimes, which is also able to reduce the friction coefficient to some extent. In USMs, both low relative velocity between the rotor and the stator and high load can be obtained in the driving stage (where the velocity of the stator is higher than that of the rotor), corresponding to boundary lubrication regime; while mixed or hydrodynamic lubrication regime can be achieved when the rotor moves in an opposite direction to the stator, where high relative velocity and low load are present. Based on this lubrication mechanism, friction coefficient can be varied to reduce the friction loss without losing the driving force. This novel driving mechanism has been 
proven to be effective in our early studies in hybrid transducer-type ultrasonic motors (HTUSMs), where both motor efficiency and torque were drastically improved with lubrication [22, 23].

Lubricant is always the key element in the machineries that require lubrication. In lubricated USMs, the ideal lubricant should be able to vary lubrication regimes corresponding to the alternating vibrations of the motor, in order to reduce friction loss and obtain high output force. Though drastic improvement in motor performance has been observed in the previous studies, the knowledge regarding the role of lubricant properties is still lacking due to the poor understanding of the complex lubrication mechanisms, which is an obstacle to establish criteria for the selection of lubricants for USMs.

In this paper, we investigate the lubricating effects of both low-traction and hightraction fluids with various viscosities in an HTUSM. After presenting a method to calculate the friction loss in HTUSM using an equivalent circuit, we experimentally demonstrate how the friction loss and motor efficiency vary using low-traction and high-traction fluids under different preloads. Then, the dependence of the mechanical characteristics of HTUSM, i.e. efficiency, torque, and no-load speed, on lubricant

viscosity is studied. Finally, the significance of high friction coefficient in boundary lubrication regime and efficient modulation of friction according to the Stribeck curve is confirmed, and the criteria for selecting lubricants for USMs are established.

\section{Materials and methods}

\subsection{Motor structure and working principle}

A Langevin transducer (diameter $\phi=25 \mathrm{~mm}$, height $h=40 \mathrm{~mm}$ ) comprising of both torsional lead zirconate titanate $\left(\mathrm{PZT}\right.$ ) disks (outer diameter $\phi_{\mathrm{o}}=25 \mathrm{~mm}$, inner 
(a)

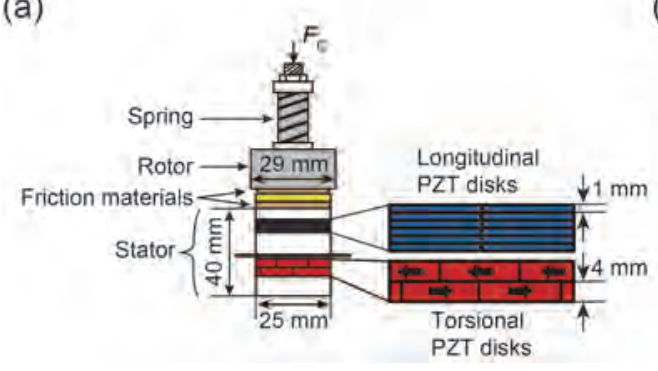

(b)

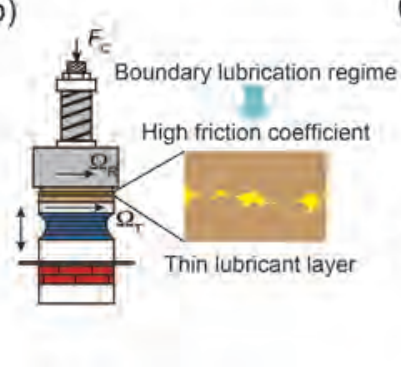

(c)

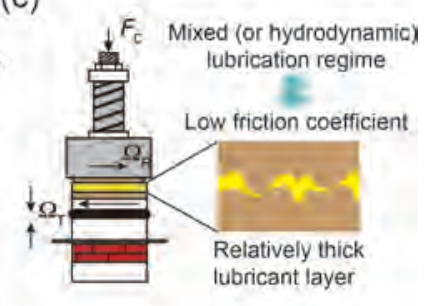

Figure 1: (a) Sketch of the HTUSM used in experiments; (b) Illustration of boundary lubrication regime in HTUSM where low relative velocity between the rotor and the stator and high loading force are present; (c) Illustration of mixed (or hydrodynamic) lubrication regime in HTUSM where high relative velocity between the rotor and the stator and low loading force are present.

diameter $\phi_{\mathrm{i}}=12 \mathrm{~mm}$, thickness $\left.d=4 \mathrm{~mm}\right)$ and longitudinal PZT disks $\left(\phi_{\mathrm{o}}=25\right.$ $\mathrm{mm}, \phi_{\mathrm{i}}=12 \mathrm{~mm}, d=1 \mathrm{~mm}$ ) was used as the stator of HTUSM, as shown in Figure 1. A rotor $(\phi=29 \mathrm{~mm})$ was pressed to the stator by a coil spring, and the preload was adjusted by varying the pressing force applied to the spring. The rotors with different heights were fabricated in order to match the resonance frequencies of longitudinal and torsional vibrations under different preloads. Lubricant was placed on top of the stator before applying preload, and the surfaces of the friction materials were completely wetted by the lubricant.

Alumina $\left(\mathrm{Al}_{2} \mathrm{O}_{3}, 99.5 \%\right)$ and zirconia $\left(\mathrm{ZrO}_{2}, 94.0 \%\right)$ were chosen as the friction materials and bonded on the stator and the rotor sides, owing to their excellent tribological performance in lubricated USMs [24]. The average roughness of $\mathrm{Al}_{2} \mathrm{O}_{3}$ and $\mathrm{ZrO}_{2}$ surfaces were 0.12 and $0.27 \mu \mathrm{m}$, respectively. According to our previous study, the surface roughness and morphology of both materials are not significantly changed during the operation of lubricated USMs 24], which is important to conduct 
Table 1: Properties of lubricants.

\begin{tabular}{|c|c|c|c|c|c|c|}
\hline & $\begin{array}{l}\text { Low-traction } \\
\text { fluid (VG 100) }\end{array}$ & $\begin{array}{l}\text { Low-traction } \\
\text { fluid (VG 220) }\end{array}$ & $\begin{array}{l}\text { Low-traction } \\
\text { fluid (VG 460) }\end{array}$ & $\begin{array}{l}\text { High-traction } \\
\text { fluid (VG 100) }\end{array}$ & $\begin{array}{l}\text { High-traction } \\
\text { fluid (VG 220) }\end{array}$ & $\begin{array}{l}\text { High-traction } \\
\text { fluid (VG 460) }\end{array}$ \\
\hline Base oil & Polyalphaolefin & Polyalphaolefin & Polyalphaolefin & $\begin{array}{l}\text { Synthetic } \\
\text { naphthene }\end{array}$ & $\begin{array}{l}\text { Synthetic } \\
\text { naphthene }\end{array}$ & $\begin{array}{l}\text { Synthetic } \\
\text { naphthene }\end{array}$ \\
\hline Additives & ZDDP & ZDDP & ZDDP & ZDDP & ZDDP & ZDDP \\
\hline $\begin{array}{l}\text { Viscosity at } 40{ }^{\circ} \mathrm{C} \\
\text { (cSt) }\end{array}$ & 104.0 & 214.5 & 474.0 & 1006 & 229.3 & 421.5 \\
\hline $\begin{array}{l}\text { Viscosity at } 100^{\circ} \mathrm{C} \\
\text { (cSt) }\end{array}$ & 15.6 & 25.7 & 46.5 & & 11.8 & 15.1 \\
\hline $\begin{array}{l}\text { Viscosity at } 20{ }^{\circ} \mathrm{C} \\
\text { (cSt) }\end{array}$ & 279.5 & 646.7 & 1561.4 & 446.7 & 1421.7 & 3358.1 \\
\hline Viscosity index & 160 & 152 & 155 & 16 & -37 & -81 \\
\hline Density $\left(\mathrm{kg} / \mathrm{m}^{3}\right)$ & 836.9 & 844.2 & 850.4 & 977.6 & 982.5 & 983.8 \\
\hline
\end{tabular}

a fair comparison using different lubricants. The dimensions of the friction materials followed our previous design described in ref. [22].

\subsection{Lubricants}

Both low-traction and high-traction fluids with various viscosities were prepared for this study. All the properties of lubricants are shown in Table 1. High-traction fluid is a category of lubricants that transmits shear force in elastohydrodynamic lubrication (EHL) regime. Therefore, they typically possess high traction coefficients which enable efficient power transmission in traction drive systems (e.g. continuously variable transmission). In contrast, low-traction fluids cannot efficiently transmit shear force in EHL regime due to their low traction coefficients, and hence are not used for traction drive. Though EHL regime is unlikely to occur in USMs due to the 
conformal contact and relatively low contact pressure $(<0.1 \mathrm{GPa})$, these two types of lubricants were selected because of their distinct properties.

For each type of lubricant, three viscosity grades (VG) were selected, i.e. VG 100, VG 220, and VG 460. According to the viscosities at $40{ }^{\circ} \mathrm{C}$ and $100{ }^{\circ} \mathrm{C}$ as well as the viscosity index, the viscosities at $20^{\circ} \mathrm{C}$ (the temperature at which the experiments were conducted) were calculated, and both types of lubricants cover a wide viscosity range. Zinc dialkyldithiophosphate (ZDDP) was the only additive used in the lubricants, since the lubricating effect might be very complex if more additives were applied. ZDDP is a common antiwear additive which reduces wear at moderate loads and temperatures. Though the working mechanisms of ZDDP in metal contact and ceramic contact are different, a reduction in friction and wear in ceramic contact (including $\mathrm{Al}_{2} \mathrm{O}_{3}$ and $\mathrm{ZrO}_{2}$ ) has been found [25]. In this experiment, preventing wear is essential because the effect of lubricants would become unclear, if the contamination of the lubricants occurs due to the formation of wear debris. In addition, from the perspective of motor lifetime, the lubricants which cannot prevent the wear of friction materials should not be selected for USMs. Therefore, ZDDP was added to the lubricants, since the effectiveness of ZDDP in preventing wear in lubricated USMs has been confirmed [24].

\subsection{Equivalent circuit for calculating friction loss}

USMs typically consist of three types of energy loss, i.e. dielectric loss, vibration loss, and friction loss. The purpose of applying lubricant to USMs is to reduce the friction loss. It is therefore important to compare not only the motor characteristics but also the friction loss when different lubricants are present. We employ an equivalent circuit which represents the torque transmission mechanism of the torsional vibrator, as shown in Figure 2, The left arm represents the electrical terminal of the 


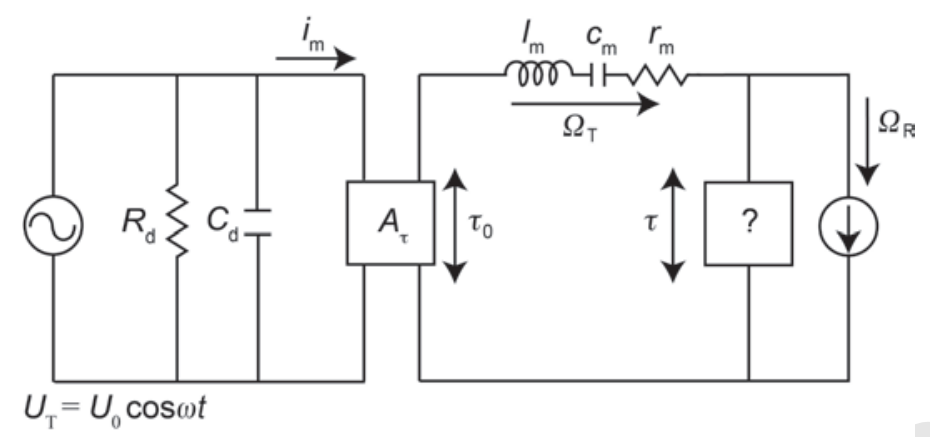

Figure 2: Equivalent circuit of HTUSM for calculating friction loss.

torsional vibrator, where $R_{\mathrm{d}}$ and $C_{\mathrm{d}}$ are the dielectric loss and clamped capacitance of torsional PZT disks while $i_{\mathrm{m}}$ is the motional current. The applied voltage to the torsional vibrator $U_{\mathrm{T}}=U_{0} \cos \omega t$, where $U_{0}$ and $\omega$ indicate the voltage amplitude and the angular frequency, respectively. The right arm represents the mechanical terminal of the torsional vibrator, where $l_{\mathrm{m}}, c_{\mathrm{m}}$, and $r_{\mathrm{m}}$ are equivalent to the moment of inertia, the reciprocal of the torsion coefficient, and the rotational friction (vibration loss) of the torsional vibrator, while $\Omega_{\mathrm{T}}, \Omega_{\mathrm{R}}$, and $\tau_{0}$ are the angular vibration velocity, the motor rotational speed, and the open-circuited torque, respectively. The electrical and the mechanical terminals are connected by the torque factor $A_{\tau}$ :

$$
\left\{\begin{array}{l}
i_{\mathrm{m}}=A_{\tau} \Omega_{\mathrm{T}}, \\
\tau_{0}=A_{\tau} U_{\mathrm{T}} .
\end{array}\right.
$$

The output torque $\tau$ is transmitted by friction force, and hence the friction loss can be calculated by subtracting the dielectric loss, the vibration loss, and the output power from the input power to the torsional transducer. It should be noted that the friction characteristics are represented by a question mark box. In dry contact, the friction coefficient $\mu$ is typically assumed to be a constant in numerical simulation, hence the friction characteristics can be represented by a twin Zener diode, as de- 
Table 2: Parameters used for calculating friction loss.

\begin{tabular}{ll}
\hline Torque factor $A_{\tau}$ & $0.00445 \mathrm{Nm} / \mathrm{V}$ \\
Free admittance $Y_{\mathrm{m} 0}$ & $2.75 \mathrm{mS}$ \\
Torsional resonance frequency $f_{\mathrm{T} 0}$ & $19.7 \mathrm{kHz}$ \\
Clamped capacitance $C_{\mathrm{d}}$ & $2.28 \mathrm{nF}$ \\
Dielectric loss $R_{\mathrm{d}}$ & $697 \mathrm{k} \Omega$ \\
Contact radius $r$ & $10.75 \mathrm{~mm}$ \\
\hline
\end{tabular}

scribed in refs. [26, 27]. However, when lubricant is present, $\mu$ is no longer a constant but varies based on the Stribeck curve. In this case, an equivalent electronic component which can represent the complex friction characteristics is difficult to find, and a question mark box is therefore used in the equivalent circuit. It also indicates that an accurate model for lubricated USMs remains challenging [22], and thus only experimental investigations are performed here. Since in this study we mainly discuss the friction loss, the efficiency defined in this paper is the transduction efficiency of the HTUSM, which is the ratio of the motor output power to the input electrical power of the torsional vibrator (longitudinal vibration does not contribute to the torque transmission). All the parameters used for calculating friction loss are summarized in Table 2 .

\subsection{Experimental setup and methods}

Figure 3 illustrates the schematic diagram of the experimental setup. The signal to drive the torsional vibrator was generated from a function generator and subsequently amplified using an amplifier and a transformer. The longitudinal vibrator was driven by the signal from the same function generator, but a phase difference was set using a phase shifter before the signal was amplified. $\Omega_{\mathrm{T}}$ was measured using an 


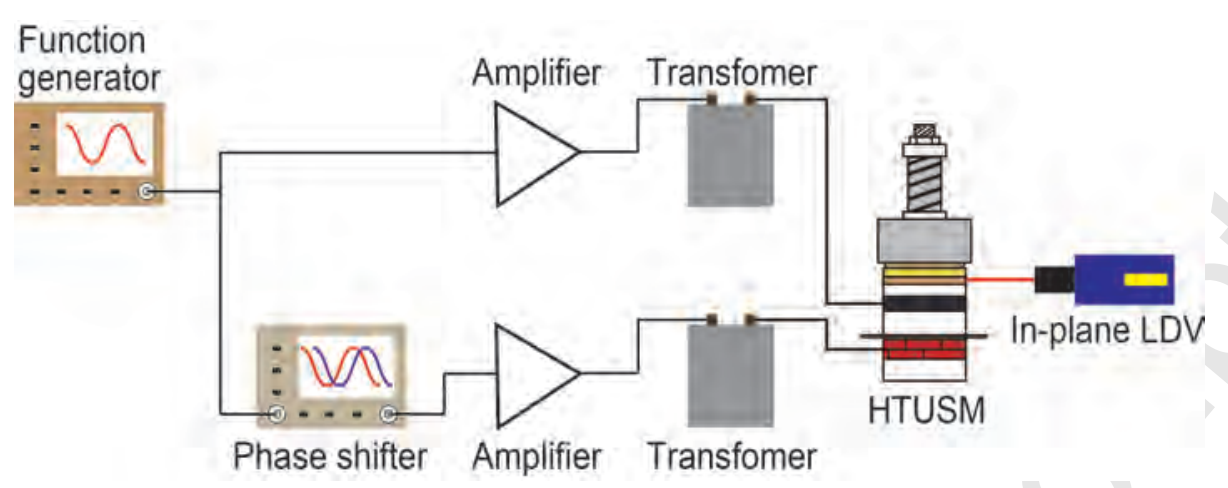

Figure 3: Schematic diagram of the experimental setup.

in-plane laser Doppler vibrometer (IPV-100, Polytec Gmbh, Waldbronn, Germany), while $\Omega_{\mathrm{R}}$ was measured by both a high-speed digital camera (M3, Integrated Design Tools, Inc., Tallahassee, USA) and a rotary encoder (Canon Inc., Tokyo, Japan). Different weights were employed to obtain the load characteristics of the motor. The electrical power to the torsional vibrator was calculated from the definition of the effective power with the voltage and current waveforms, and also verified using a digital power meter (Power HiTESTER 3332, Hioki, Ueda, Japan).

The applied voltage to the longitudinal PZT disks was fixed at $61 \mathrm{~V}_{\text {rms }}$ for all the measurements, in order to avoid the effect of longitudinal vibration on motor transduction efficiency. Under different preloads, the maximum motor efficiency is achieved at different $U_{0}$. In general, the maximum efficiency under low preloads is obtained at low $U_{0}$, while high $U_{0}$ is required to achieve maximum efficiency under high preloads. The details regarding this phenomenon have been discussed in our previous studies [22, 26]. In the present work, $U_{0}$ was tuned to find the maximum efficiency under each preload (the optimal $U_{0}$ values for the same type of lubricant with different viscosities under the same preload had little variation (maximum 3.2\%), but the optimal $U_{0}$ values for high-traction fluids were higher (from $27.4 \%$ to $73.7 \%$ 
under different preloads) than that for low-traction fluids). The $U_{0}$ values used in the experiments ranged from 13.44 to $147.81 \mathrm{~V}_{\mathrm{rms}}$, corresponding to a preload range from 171 to 682 N. The no-load speed and maximum torque under each preload were measured with $U_{0}$, at which maximum efficiency can be achieved. The maximum torque under different conditions was calculated from the weights that just stopped the motor. All the experiments were conducted at room temperature $\left(20^{\circ} \mathrm{C}\right)$; for each measurement, the motor was operated for a short time (less than $10 \mathrm{~s}$ ) to avoid the temperature rise. Thus, the viscosities of the lubricants were not significantly varied during each measurement. Prior to changing the lubricant, the surfaces of the friction materials were cleaned with toluene for $15 \mathrm{~min}$, followed by another 15-min cleaning with isopropanol, both in an ultrasonic cleaner, in order to avoid any residuals of the previously tested lubricants. All the measurements were performed five times under each condition in order to improve the statistics.

\section{Results}

Different contributions of power consumption in lubricated HTUSMs under various preloads using both low-traction and high-traction fluids with a viscosity grade of 100 are illustrated in Figure 4. The dielectric loss of the torsional PZT disks only consumed very limited amount of the input power $(\approx 1 \%)$ under all preloads for both types of lubricants. The vibration loss was relatively high under low preloads, but decreased with the preload increasing and became saturated under high preloads. When low-traction fluid was applied, the vibration loss was higher than that using high-traction fluid, and the difference under low preloads was rather distinct. More significant difference was found for the two types of lubricants in friction loss and motor efficiency. It is clearly shown that friction loss is the dominant loss in HTUSMs, particularly under high preloads. The friction loss using low-traction fluid was higher 

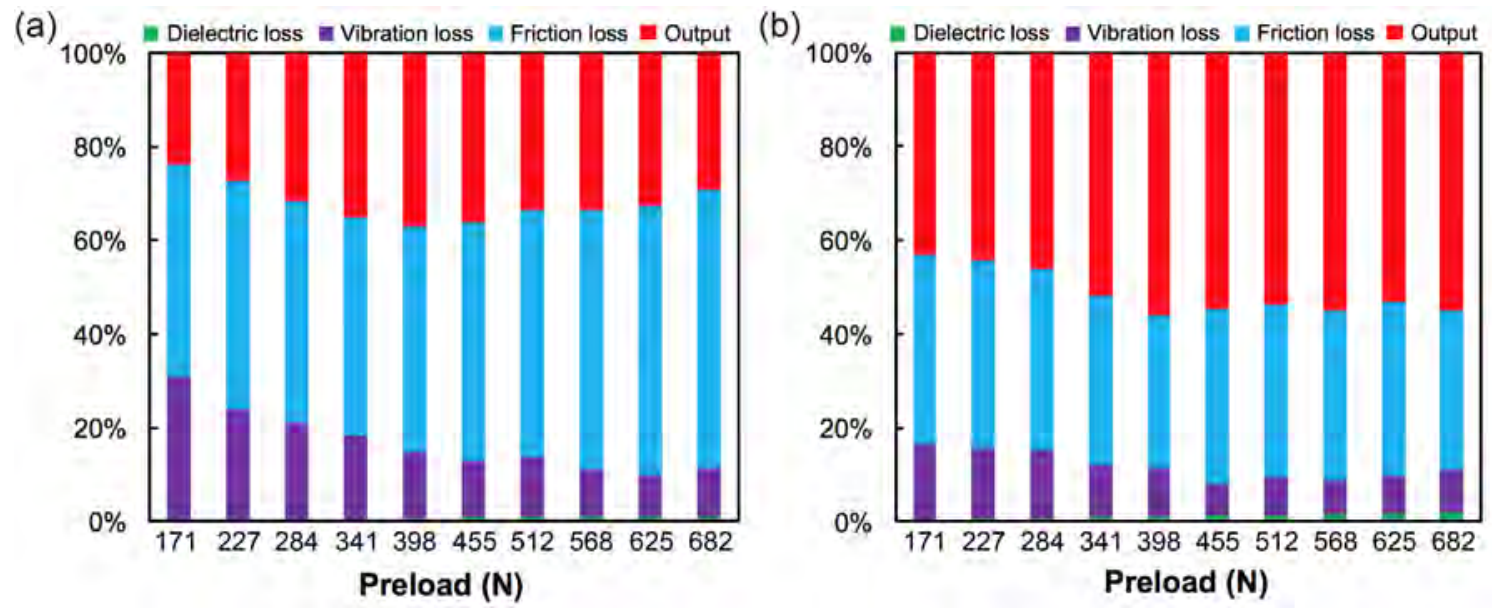

Figure 4: The percentage of different contributions of power consumption in lubricated HTUSMs using (a) low-traction fluid (VG 100) and (b) high-traction fluid (VG 100) under different preloads.

than that lubricated by high-traction fluid at the whole preload range, resulting in lower motor efficiency.

The dependencies of the motor efficiency and the percentage of friction loss on static preload with all lubricant viscosities are shown in Figures 5 and 6. Surprisingly, the motor efficiency and the percentage of friction loss did not show any viscosity dependence, resulting in similar efficiency and percentage of friction loss under all applied preloads. With low-traction fluids, the motor efficiency initially increased with the preload increasing, then saturated under moderate preloads but finally decreased under high preloads. Correspondingly, the percentage of friction loss showed a general trend of increasing, while it increased more rapidly under high preloads than that under low preloads. In contrast, when high-traction fluids were applied, the motor efficiency increased with the preload increasing, and was maintained at high values $(>53 \%)$. In terms of the percentage of friction loss, it initially decreased until it reached the lowest value, and then was kept at relatively low values $(<37 \%)$ under high preloads. 
(a)

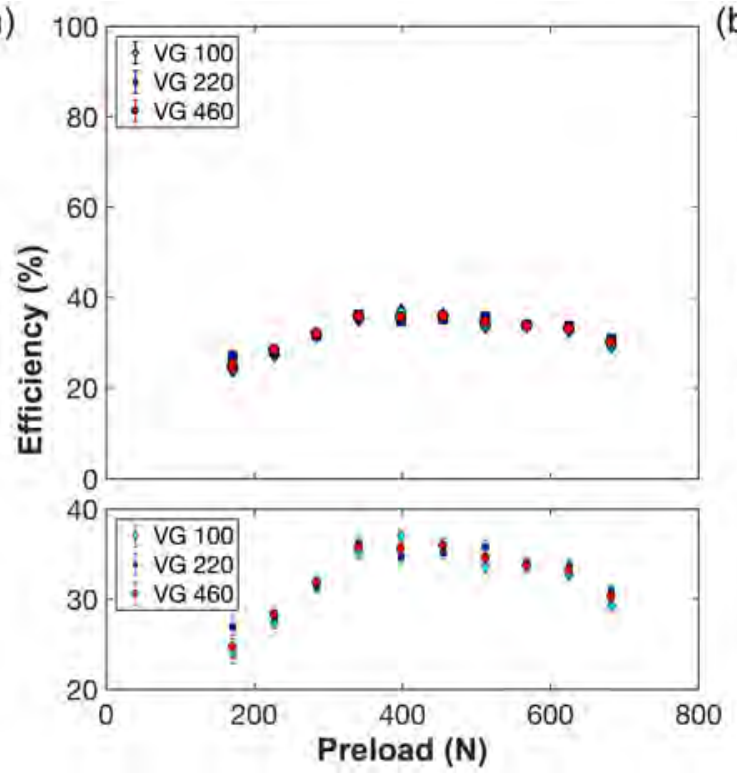

(b)

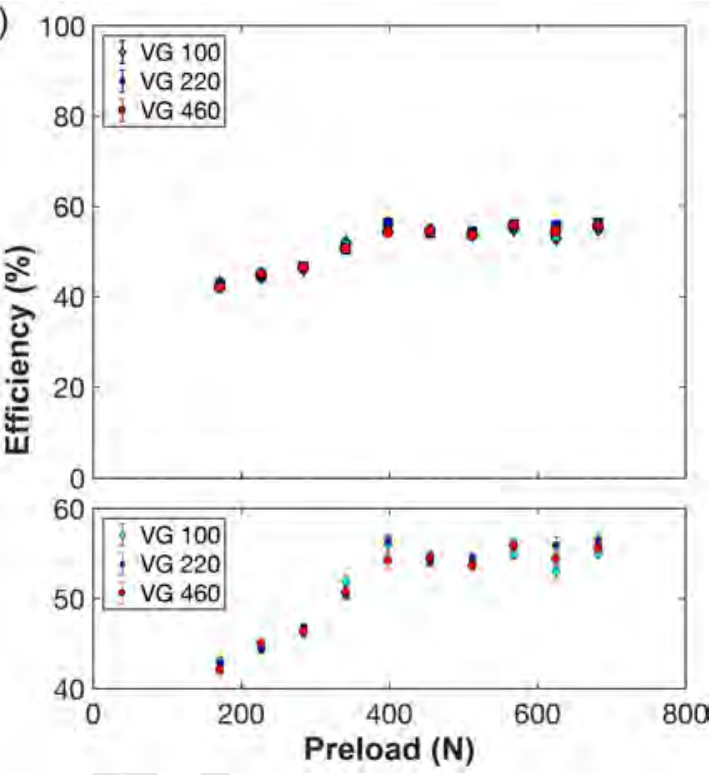

Figure 5: Motor efficiency as a function of static preload using (a) low-traction fluids and (b) high-traction fluids with different viscosities. The upper figures show the data plots in a large scale for $y$-axis (from 0 to 100\%), while the lower figures plot the same data as the upper ones, but in a small scale for $y$-axis in order to show the standard errors clearly.

The maximum torque and no-load speed using different lubricants were also examined, as illustrated in Figures 7 and 8. It should be noted that the maximum torque and no-load speed were measured with the applied voltages to the torsional vibrator $U_{0}$, at which the highest motor efficiency was obtained under different preloads. Therefore, the results in Figure 7 are not the absolute maximum torque of motor under each preload, which should be even larger with a higher $U_{0}$ value [23, 26]. Since the $U_{0}$ values for the same type of lubricant with different viscosities were rather close but varied for different types of lubricants, the comparison was only conducted for the same type of lubricant. The maximum torque using both types of lubricants showed an increasing trend at the entire preload range. The no-load speed with hightraction fluids increased with the preload increasing, while with low-traction fluids, 
(a)

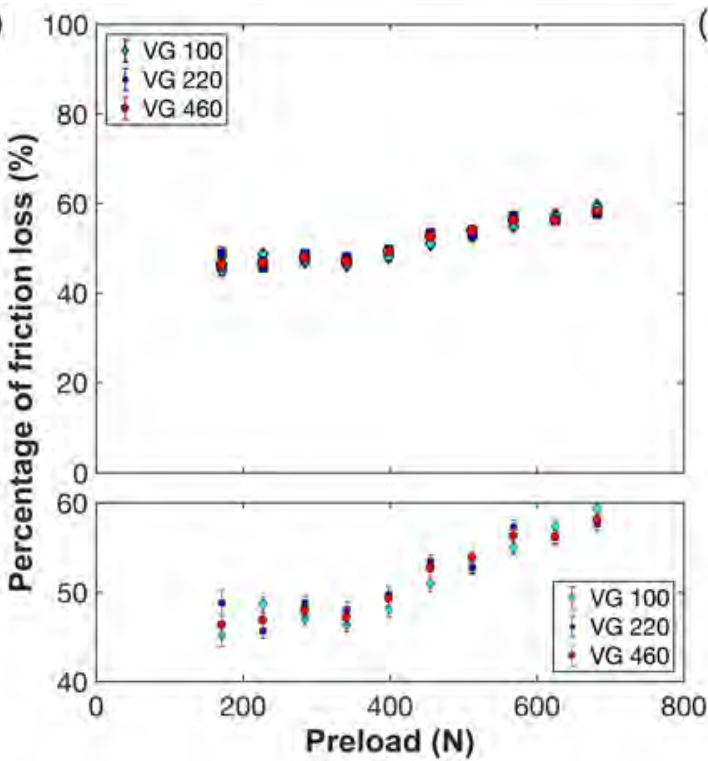

(b)

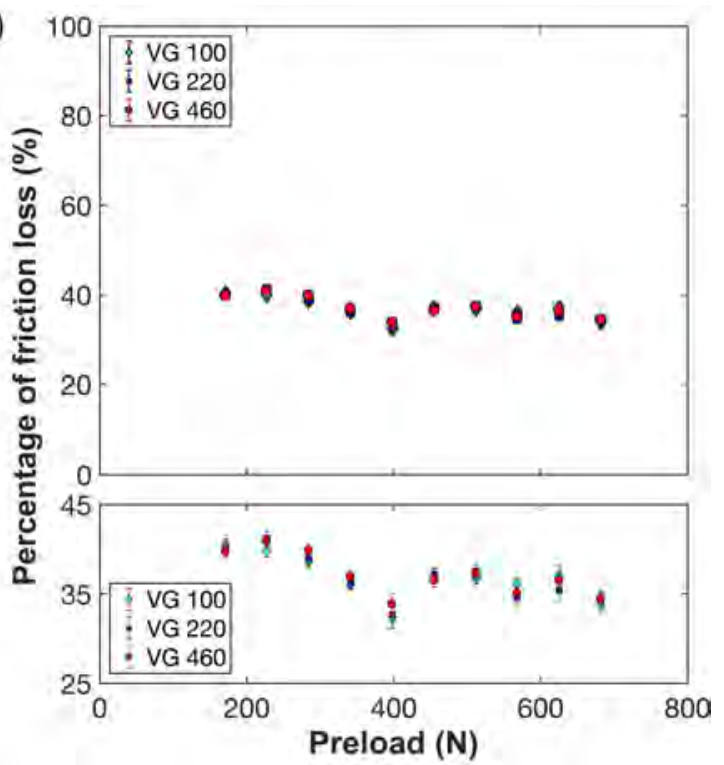

Figure 6: The percentage of friction loss as a function of static preload using (a) low-traction fluids and (b) high-traction fluids with different viscosities. The upper figures show the data plots in a large scale for $y$-axis (from 0 to 100\%), while the lower figures plot the same data as the upper ones, but in a small scale for $y$-axis in order to show the standard errors clearly.

(a)

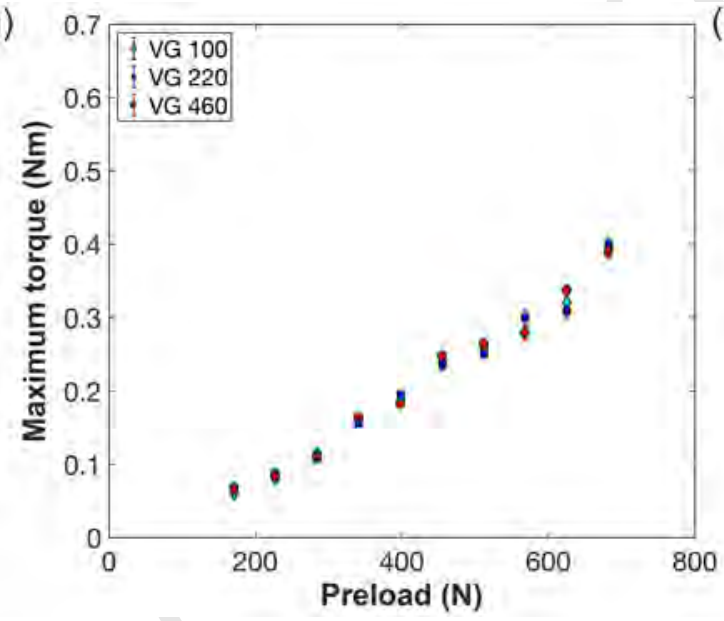

(b)

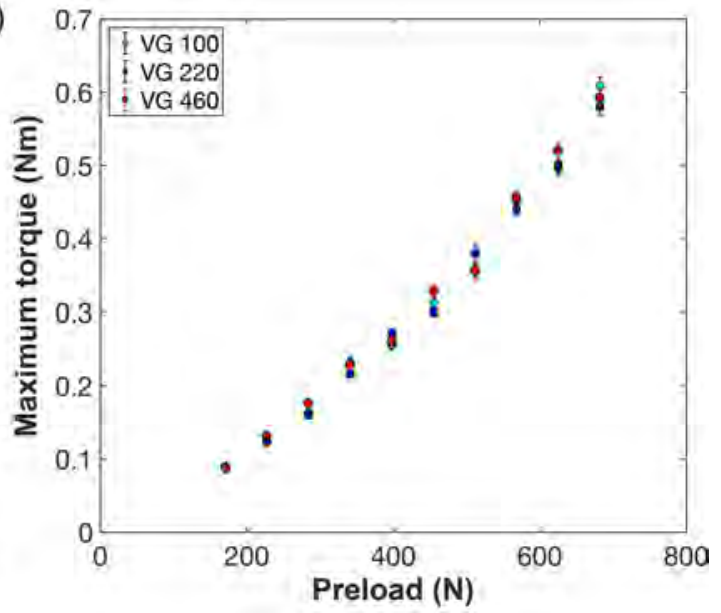

Figure 7: Maximum torque as a function of static preload using (a) low-traction fluids and (b) high-traction fluids with different viscosities. 
(a)

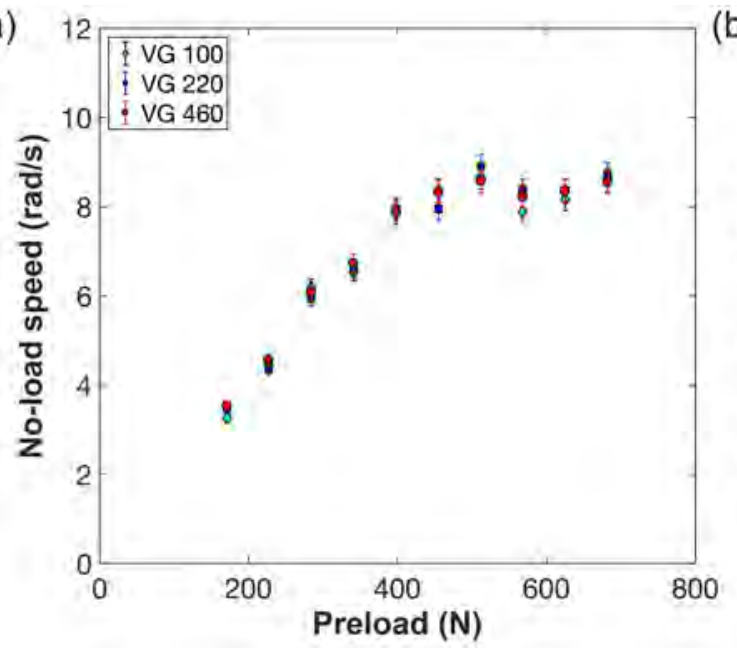

(b)

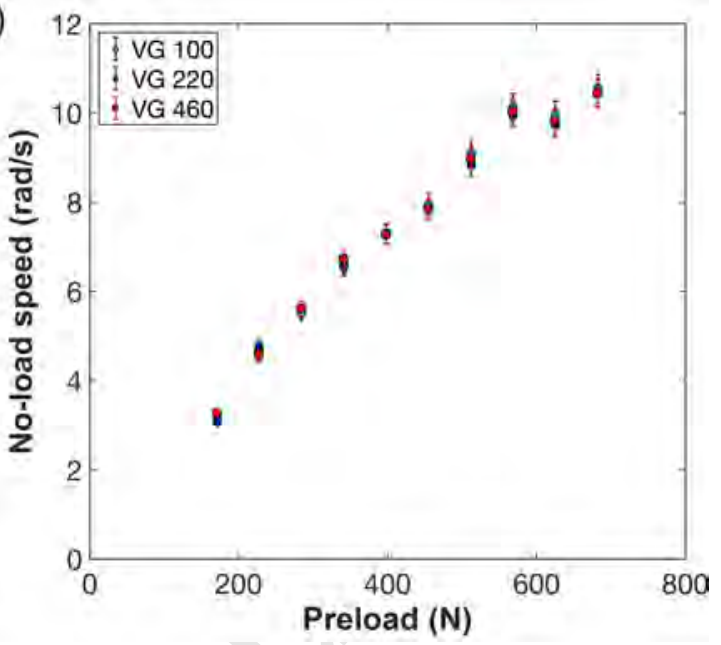

Figure 8: No-load speed as a function of static preload using (a) low-traction fluids and (b) high-traction fluids with different viscosities.

the no-load speed initially increased until it became saturated when the preload was higher than 500 N. Again, the maximum torque and no-load speed did not show any viscosity dependence under all preloads, which is the same with motor efficiency and friction loss.

\section{Discussion}

High-traction fluids showed significant superiority to low-traction fluids in terms of motor efficiency and reduction in friction loss. In order to understand the distinct lubricating effects, the friction coefficients under two different conditions were measured. Owing to the difficulties in measuring instantaneous friction coefficients during motor operation, the friction coefficient was estimated from the falling curve right after switching off the input power to the HTUSM, which shows the friction between the rotor and the stator without ultrasonic vibration [11, 24]. The retarding 
torque of USMs $T_{\mathrm{R}}$ (the torque without ultrasonic vibration) can be expressed as

$$
T_{\mathrm{R}}=J \frac{d \Omega_{\mathrm{R}}}{d t}=J \frac{\Omega_{\mathrm{R} 1}-\Omega_{\mathrm{R} 2}}{t_{\mathrm{f}}} .
$$

Here, $J$ and $t_{\mathrm{f}}$ are the moment of inertia of the rotor and the fall time. $\Omega_{\mathrm{R} 1}$ and $\Omega_{\mathrm{R} 2}$ represent the highest and the lowest rotational speeds within $t_{\mathrm{f}}$. $T_{\mathrm{R}}$ can also be obtained from

$$
T_{\mathrm{R}}=\mu F r
$$

where $F$, and $r$ represent the preload and the contact radius, respectively. Combining Eqs. (2) and (3), $\mu$ can be calculated as

$$
\mu=\frac{J\left(\Omega_{\mathrm{R} 1}-\Omega_{\mathrm{R} 2}\right)}{t_{\mathrm{f}} F r} .
$$

In lubricated condition, $\mu$ is dependent on the relative velocity of the sliding surfaces. Therefore, the obtained $\mu$ value is the average value within $t_{\mathrm{f}}$. Condition (a) in Table III was chosen to indicate the friction coefficients in the stage where the reverse torque occurs $\left(\Omega_{\mathrm{T}}<\Omega_{\mathrm{R}}\right)$, while condition (b) indicates the driving stage $\left(\Omega_{\mathrm{T}} \geqslant \Omega_{\mathrm{R}}\right)$. Here, $P$ represents the apparent contact pressure under $F(P=F / A$, where $A$ is the contact area), and $\bar{V}$ is the average sliding velocity within $t_{\mathrm{f}}$, which is calculated as

$$
\bar{V}=\frac{1}{t_{\mathrm{f}}} \int_{t_{\mathrm{f}}} \Omega_{\mathrm{R}} r d t .
$$

For condition (a), the motor was stopped from $\Omega_{1}=18.6 \mathrm{rad} / \mathrm{s}$ to $\Omega_{2}=13.95 \mathrm{rad} / \mathrm{s}$, resulting in a $\bar{V}$ value of approximately $175 \mathrm{~mm} / \mathrm{s}$; for condition (b), the motor was stopped from $\Omega_{1}=4.65 \mathrm{rad} / \mathrm{s}$ to $\Omega_{2}=0$, resulting in a $\bar{V}$ value of approximately 25 $\mathrm{mm} / \mathrm{s}$. Owing to low $P$ and high $\bar{V}$, condition (a) should be able to represent mixed lubrication regime; while boundary lubrication regime is represented by condition (b) because of high $P$ and low $\bar{V}$. Hydrodynamic lubrication is extremely difficult to achieve in HTUSMs due to the parallel contact surfaces (the lifting pressure is 
Table 3: Friction coefficients measured at different conditions.

\begin{tabular}{|c|c|c|c|c|c|c|}
\hline & $\begin{array}{l}\text { Low-traction } \\
\text { fluid (VG 100) }\end{array}$ & $\begin{array}{l}\text { Low-traction } \\
\text { fluid (VG 220) }\end{array}$ & $\begin{array}{l}\text { Low-traction } \\
\text { fluid (VG 460) }\end{array}$ & $\begin{array}{l}\text { High-traction } \\
\text { fluid (VG 100) }\end{array}$ & $\begin{array}{l}\text { High-traction } \\
\text { fluid (VG 220) }\end{array}$ & $\begin{array}{l}\text { High-traction } \\
\text { fluid (VG 460) }\end{array}$ \\
\hline $\begin{array}{l}\text { (a) } F=57 \mathrm{~N}, P \\
=6 \mathrm{MPa}, \bar{V}=175 \\
\mathrm{~mm} / \mathrm{s}\end{array}$ & $0.014 \pm 0.001$ & $0.017 \pm 0.002$ & $0.026 \pm 0.002$ & $0.043 \pm 0.003$ & $0.062 \pm 0.003$ & $0.087 \pm 0.003$ \\
\hline $\begin{array}{l}\text { (b) } F=682 \mathrm{~N}, P \\
=76 \mathrm{MPa}, \bar{V}=25 \\
\mathrm{~mm} / \mathrm{s}\end{array}$ & $0.067 \pm 0.003$ & $0.079 \pm 0.003$ & $0.082 \pm 0.004$ & $0.103 \pm 0.004$ & $0.121 \pm 0.005$ & $0.144 \pm 0.005$ \\
\hline
\end{tabular}

hard to build without a converging entry for the lubricant entrainment), unless the

rotor and the stator are detached due to longitudinal vibration. Under high $F$, the contact duration is $2 \pi$ so that the rotor and the stator are always in contact; under low $F$, the contact duration might be smaller than $2 \pi$, but the period for detachment in one period should be very limited due to the weak longitudinal vibration. All the measurements were performed five times under each condition, and individual measurement consumed less than $5 \mathrm{~s}$, which prevented the temperature rise. The average values of $\mu$ and their standard errors are summarized in Table 3 .

For both types of lubricants, $\mu$ showed viscosity dependence at each condition, giving higher $\mu$ when the viscosity was increased. The big difference in $\mu$ between the two conditions at each viscosity proved that $\mu$ is indeed able to be greatly varied during motor operation owing to the presence of lubricant. The $\mu$ values of high-traction fluids were considerably higher in condition (b) than those of low-traction fluids at the entire range of tested viscosities, though the $\mu$ values of high-traction fluids in condition (a) were also higher. The high $\mu$ values of high-traction fluids in boundary lubrication regime is believed to be the most significant reason for the higher motor efficiency than that using low-traction fluids. As expected, it is essential to possess 
high $\mu$ in the driving stage of lubricated USMs through boundary lubrication; otherwise the driving force would be significantly lowered, leading to low motor efficiency, which is the case using low-traction fluids. Though it is also important to achieve low $\mu$ in mixed lubrication regime in order to reduce the reverse torque, the higher

240 regime is a more dominant factor for achieving high-performance lubricated USMs, if the range of variation in $\mu$ is comparable among different types of lubricants. The high average $\mu$ value in one period of vibration with high-traction fluids also lowers $\Omega_{\mathrm{T}}$ [20, 23], which decreases the vibration loss (see Figure 4).

We take the results obtained from low-traction and high-traction fluids with a viscosity grade of 100 as an example to illustrate how the friction loss varied under different conditions. The friction loss $P_{\mathrm{F}}$ can be calculated as [3, 28]

$$
P_{\mathrm{F}}=\frac{1}{t_{\mathrm{f}}} \int_{0}^{t} f(t)\left[v_{\mathrm{s}}(t)-v_{\mathrm{r}}(t)\right] d t .
$$

Here, $f, v_{\mathrm{s}}$, and $v_{\mathrm{r}}$ (all time-dependent) are the tangential force between the rotor and the stator and the tangential velocities of the stator and the rotor, respectively, where $f$ is mainly determined by the friction force. The slip velocity $\Delta v$ in one period of vibration $T$ is calculated as

$$
\Delta v=\frac{1}{T} \int_{0}^{T}\left|v_{\mathrm{s}}(t)-v_{\mathrm{r}}(t)\right| d t
$$

The measured input power $P_{\text {in }}, P_{\mathrm{F}}$, and $\Delta v$ using low-traction and high-traction fluids (VG 100) under different $F$ are shown in Figure 9. All the three parameters exhibited increasing trends when $\mathrm{F}$ increased, irrespective of lubricant types, resulting from the increasing $U_{0}$ values when $F$ became higher. Under most of the applied $F$, the $P_{\text {in }}$ values using high-traction fluid were higher than that using low-traction fluid. 

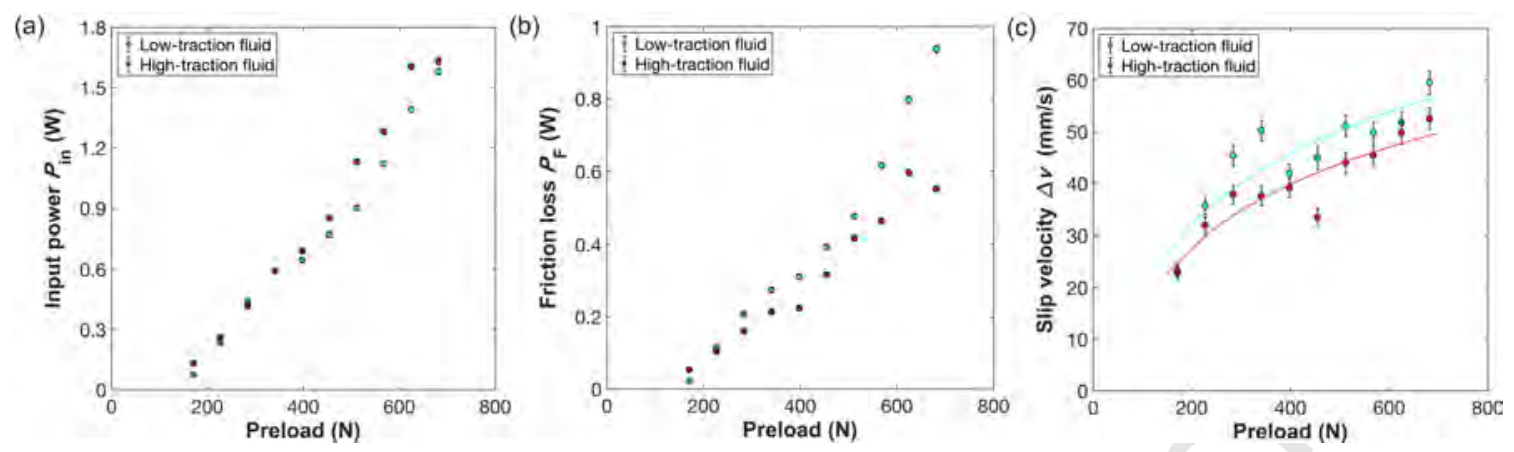

Figure 9: (a) Input power $P_{\text {in }}$, (b) friction loss $P_{\mathrm{F}}$, and (c) slip velocity $\Delta v$ in one period of vibration $T$ as functions of static preload using low-traction and high-traction fluids (VG 100). All the values were measured when the highest efficiency was achieved under each preload.

high-traction fluid except under very low $F$, corresponding to larger $\Delta v$ and lower efficiency (see Figure 5). The low efficiency is mainly caused by high $P_{\mathrm{F}}$ and low output power. Large $\Delta v$ is one important reason to induce high $P_{\mathrm{F}}$, as analyzed in ref. [13], while low output power indicates that the friction modulation by lowtraction fluid was not ideal. The smaller $\Delta v$ using high-traction fluid than that using low-traction fluid was mainly due to its higher average $\mu$, resulting in less $P_{\mathrm{F}}$ especially under high $F$. Less $P_{\mathrm{F}}$ and vibration loss with high-traction fluids led to much higher efficiency than that using low-traction fluids. The large output power and high efficiency using high-traction fluids under high $F$ is a strong evidence that the friction modulation is efficient with this type of lubricant, which is not possible in dry contact owing to the weak longitudinal vibration under high $F$.

Somewhat counter intuitively, all the mechanical characteristics of motor were very close when different viscosities of lubricants were applied (see Figures 558), though the $\mu$ values in boundary and mixed lubrication regimes were different. It indicates that hydrodynamic lubrication did not play a significant role even under low preloads; otherwise the motor characteristics should be quite distinct when the 
lubricants with different viscosities are used (the drag force in hydrodynamic lubrication regime is larger with high-viscosity lubricant than that using low-viscosity lubricant). It also indicates that the average friction force and slip in one $T$ are fairly 
preloads in addition to high $\mu$ in boundary lubrication regime, leading to low friction loss and high efficiency. This study confirmed that high $\mu$ in boundary lubrication regime and the efficient modulation of the friction force are essential for achieving high-performance lubricated USMs, which should be the criteria for selecting lubricants for USMs. Since it may be difficult to increase $\mu$ in boundary lubrication regime for high-traction lubricants due to the potential severe wear, further improvement in motor performance can still be expected if the $\mu$ value in mixed lubrication regime is reduced. The results obtained in this work also provide a step forward in understanding the complex lubrication mechanisms in USMs.

\section{Acknowledgements}

This work was supported by the Japan Society for the Promotion of Science (JSPS) KAKENHI Grant Number 15K13896 and a Grant-in-Aid for JSPS Research Fellows (No. 26011842). The authors are indebted to Dr. Yoji Sunagawa (Drive Train Lubricants Group, Lubricants Research Laboratory, Idemitsu Kosan Co., Ltd.) for the insightful discussions and providing all the lubricants. They also appreciate the staff members of the Precision and Manufacturing Center (Technical Department, Tokyo Institute of Technology) for machining the metal components of the motors used in the experiment.

\section{References}

[1] S. Ueha, Y. Tomikawa, Ultrasonic Motors - Theory and Applications, Oxford Science Publications, New York, 1993.

[2] K. Uchino, Piezoelectric Actuators and Ultrasonic Motors, Kluwer Academic Publisher, New York, 1996. 
[3] T. Maeno, T. Tsukimoto, A. Miyake, Finite-element analysis of the rotor/stator contact in a ring-type ultrasonic motor, IEEE Trans. Ultrason., Ferroelectr., Freq. Control 39 (1992) 668-674.

[4] T. Maeno, I. Okumura, T. Tsukimoto, T. Mori, How to make high-efficiency ultrasonic motors, in: Proc. Intl. Conf. Acoustics, 2004, pp. I409-I412.

[5] T. Morita, M. Kurosawa, T. Higuchi, Design of a cylindrical ultrasonic micromotor to obtain mechanical output, Jpn. J. Appl. Phys. 35 (1996) 3251-3254.

[6] M. K. Kurosawa, O. Kodaira, Y. Tsuchitoi, T. Higuchi, Transducer for high speed and large thrust ultrasonic linear motor using two sandwich-type vibrators, IEEE Trans. Ultrason., Ferroelectr., Freq. Control 45 (1998) 1188-1195.

[7] M. Aoyagi, Y. Tomikawa, Improvement in performance of longitudinal and torsional vibrator combination-type ultrasonic motor, Jpn. J. Appl. Phys. 38 (1999) $3342-3346$.

[8] J. Satonobu, D. Lee, K. Nakamura, S. Ueha, Improvement of the longitudinal vibration system for the hybrid transducer ultrasonic motor, IEEE Trans. Ultrason., Ferroelectr., Freq. Control 47 (2000) 216-221.

[9] M. Takano, M. Takimoto, K. Nakamura, Electrode design of multilayered piezoelectric transducers for longitudinal-bending ultrasonic actuators, Acoust. Sci. Technol. 32 (2011) 100-108.

[10] F. R. M. Romlay, W. A. W. Yusoff, K. A. M. Piah, Increasing the efficiency of traveling wave ultrasonic motor by modifying the stator geometry, Ultrasonics 64 (2016) 177-185. 
[11] K. Nakamura, M. Kurosawa, H. Kurebayashi, S. Ueha, An estimation of load characteristics of an ultrasonic motor by measuring transient responses, IEEE Trans. Ultrason., Ferroelectr., Freq. Control 38 (1991) 481-485.

[12] K. Uchino, Piezoelectric ultrasonic motors: overview, Smart Mater. Struct. 7 (1998) 273-285.

[13] T. Ishii, T. Shinkoda, S. Ueha, K. Nakamura, M. Kurosawa, Efficiency improvement of an ultrasonic motor driven with rectangular waveform, Jpn. J. Appl. Phys. 35 (1996) 3281-3285.

[14] T. Ishii, H. Takahashi, S. Ueha, et al., A low-wear driving method of ultrasonic motors, Jpn. J. Appl. Phys. 38 (1999) 3338-3341.

[15] A. Glazounov, S. Wang, Q. Zhang, C. Kim, High-efficiency piezoelectric motor combining continuous rotation with precise control over angular positioning, Appl. Phys. Lett 75 (1999) 862-864.

[16] K. Nakamura, T. Ito, M. Kurosawa, S. Ueha, A trial construction of an ultrasonic motor with fluid coupling, Jpn. J. Appl. Phys. 29 (1990) L160-L161.

[17] Y. Yamayoshi, Ultrasonic motor not using mechanical friction force, Int. J. Appl. Eletromagn. Mater 3 (1992) 179-182.

[18] T. Yamazaki, J. Hu, K. Nakamura, S. Ueha, Trial construction of a noncontact ultrasonic motor with an ultrasonically levitated rotor, Jpn. J. Appl. Phys. 35 (1996) 3286-3288.

[19] K. Nakamura, M. Maruyama, S. Ueha, A new ultrasonic motor using electrorheological fluid and torsional vibration, Ultrasonics 34 (1996) 261-264. 
[20] W. Qiu, Y. Hong, Y. Mizuno, W. Wen, K. Nakamura, Non-contact piezoelectric

[28] H. Hirata, S. Ueha, Characteristics estimation of a traveling wave type ultrasonic motor, IEEE Trans. Ultrason., Ferroelectr., Freq. Control 40 (1993) 402-406. 
Wei Qiu received the B.E. degree in electrical engineering from Nantong University, Nantong, China, in 2009, M.Sc degree in electrical and electronic engineering from The University of Hong Kong, Hong Kong, China, in 2010, M.E. and Dr.Eng. degrees in information processing (specialized in ultrasonics) from Tokyo Institute of Technology, Yokohama, Japan, in 2012 and 2015, respectively. He stayed at Tribology Group, Department of Mechanical Engineering, Imperial College London, UK, as a visiting student in 2014.

From 2014 to 2015, he was a Research Fellow (DC2) of the Japan Society for the Promotion of Science (JSPS). From 2015 to 2016, he worked at the Precision and Intelligence Laboratory (presently, Institute of Innovative Research), Tokyo Institute of Technology, as a Research Fellow (PD) of JSPS. Since 2016, he has become an H.C. Ørsted COFUND Postdoc Fellow (co-funded by Marie Curie Actions) at Department of Physics, Technical University of Denmark. His research interests include microscale acoustofluidics as well as ultrasonic motors and actuators.

Dr. Qiu is the recipient of the Young Scientist Award at the Symposium on Ultrasonic Electronics in 2013, the RWB Stephens Prize at 2015 International Congress on Ultrasonics, and the Seiichi Tejima Doctoral Dissertation Award in 2016.

Yosuke Mizuno received the B.E., M.E., and Dr.Eng. degrees in electronic engineering from the University of Tokyo, Japan, in 2005, 2007, and 2010, respectively.

From 2007 to 2010, he was involved in Brillouin optical correlation-domain reflectometry for his Dr.Eng. degree at the University of Tokyo. From 2007 to 2010, he was a Research Fellow (DC1) of the Japan Society for the Promotion of Science (JSPS). From 2010 to 2012, as a Research Fellow (PD) of JSPS, he worked on polymer optics at Tokyo Institute of Technology, Japan. In 2011, he stayed at BAM Federal Institute for Materials Research and Testing, Germany, as a Visiting Research Associate. Since 2012, he has been an Assistant Professor in the Precision and Intelligence Laboratory (presently, Institute of Innovative Research), Tokyo Institute of Technology, where he is active in fiber-optic sensing, polymer optics, and ultrasonics.

Dr. Mizuno is the winner of the Ando Incentive Prize for the Study of Electronics 2011, the Konica Minolta Imaging Science Award 2014, the Japanese Society of Applied Physics (JSAP) Young Scientist Presentation Award 2015, and the Optical Society of Japan (OSJ) Optics Paper Award 2017, the Optical Design Award 2018. He is a Senior Member of the IEEE Photonics Society and a member of the JSAP, the OSJ, and the Institute of Electronics, Information, and Communication Engineers of Japan.

Koshi Adachi graduated in Mechanical Engineering from Tohoku University in 1988 and obtained his Ph.D. degree for research in Tribology from Tohoku University, Japan, in 1998. He started to work as a research associate in 1990, and he is currently a full professor at the Faculty of Engineering, Tohoku University. He is the head of Laboratory of Tribology and Nanointerface Engineering and the director of Center for Tribologically-based Machine Design, in Division of Mechanical Engineering, Tohoku University. His research interests span a wide range of tribology, including fundamentals and applications of tribology, with a particular interest in friction and wear mechanisms of advanced materials, technologies for super-low friction such as surface texturing and new coatings, science and technology for running-in control and functional interface (nanointerface) formed during friction automatically, environmentally friendly mechanical systems with water and gas lubrication, friction drive with ultrasonic and surface acoustic wave for precise positioning systems as well as control of tribo-chemical reaction.

Prof. Adachi has won eighteen awards covering different aspects of his research, including the Best Paper Awards from The Japan Society of Mechanical Engineers in 1999 and from 
Japanese Society of Tribologists in 2003, 2014, and 2018. He serves as the editorial board member for six international journals, such as International Journal of WEAR, Lubrication Science, and so on.

Kentaro Nakamura received the B.E., M.E., and Dr.Eng. degrees from Tokyo Institute of Technology, Japan, in 1987, 1989, and 1992, respectively.

Since 2010, he has been a Professor in the Precision and Intelligence Laboratory (presently, Institute of Innovative Research), Tokyo Institute of Technology. His research field is the applications of ultrasonic waves, measurement of vibration and sound using optical methods, and fiber-optic sensing.

Prof. Nakamura is the winner of the Awaya Kiyoshi Award for Encouragement of Research from the Acoustical Society of Japan (ASJ) in 1996, and the Best Paper Awards from the Institute of Electronics, Information and Communication Engineers (IEICE) in 1998 and from the Symposium on Ultrasonic Electronics in 2007 and 2011. He also received the Japanese Journal of Applied Physics Editorial Contribution Award from the Japan Society of Applied Physics (JSAP) in 2007, the Optical Design Award 2018. He is a member of the IEEE, the ASJ, the JSAP, the IEICE, and the Institute of Electrical Engineers of Japan. He served as the president of ASJ from 2015 to 2017. 
- The influence of lubricant properties on the performance of ultrasonic motors is studied.

- High-traction fluids show significant superiority to low-traction fluids in terms of motor efficiency and reduction of friction loss.

- High friction coefficient in boundary lubrication regime and efficient modulation of friction are critical to achieve high-performance ultrasonic motors with lubrication.

- The results show that the motor performance is independent on lubricant viscosity in a wide range of viscosity.

- The criteria of selecting lubricants for ultrasonic motors are established. 